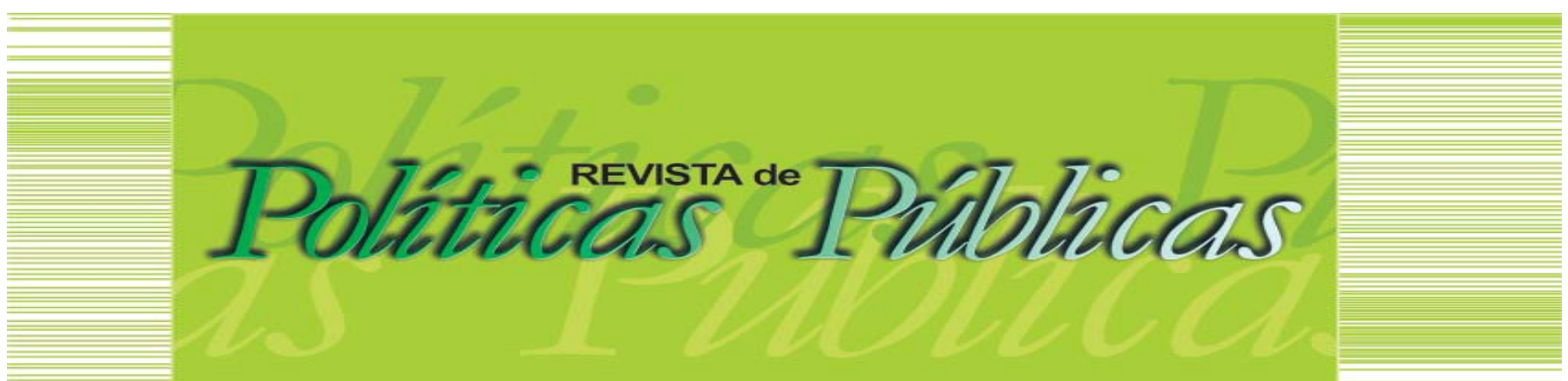

\title{
O COVID-19 E AS VÍSCERAS DA NECROPOLÍTICA BRASILEIRA SOBRE A SAÚDE DOS CORPOS NEGROS
}

\author{
Eliaidina Wagna Oliveira da Silva ${ }^{1}$
}

\begin{abstract}
Resumo
Esta pesquisa integra literaturas sobre necropoder e segregação dos corpos negros como políticas de descartes raciais. A leitura de Borges (2020), Fernandes (2008, 2017), Foucault (2005), Gomes (2019), Nascimento (2016), Mbembe (2019) denuncia uma necropolítica de semente colonizadora, que é voltada ao genocídio negro, e encontra na pandemia do covid19 a estufa para as mortes etiquetadas pelo racismoDestaca que a maior mortandade da peste pandêmica a agir dentro desses grupos marginalizados é a sistematização secular de um segregacionismo não oficializado, mas resistente. Concluique o mito da democracia racial é o mecanismo de marginalização mais agressivo a ser combatido, porque é o que mais reflete na desumanização das vidas negras, ao desacreditar medidas de inclusão social positiva.
\end{abstract}

Palavras-chave: Necropolítica. Covid-19. Racismo. Democracia Racial.

\section{THE COVID-19 AND THE VISSCERA OF THE BRAZILIAN NECROPOLITICS CONCERNING THE HEALTH OF BLACK BODIES}

\begin{abstract}
This research integrates literature on necropower and segregation of black bodies as racial discard policies. Reading Borges (2020), Fernandes (2008, 2017), Foucault (2005), Gomes (2019), Nascimento (2016), Mbembe (2019) denounces a necropolitics of colonizing seed, which is focused on black genocide, and finds in the covid-19 pandemic, the stove for deaths tagged by racism Highlights that the greatest death toll from the pandemic plague acting within these marginalized groups is the secular systematization of an unofficial but resistant segregationism. It is concluded that the myth of racial democracy is the most aggressive marginalization mechanism to be fought, because it is the one that most reflects in the dehumanization of black lives, by discrediting measures of positive social inclusion.
\end{abstract}

Keywords: Necropolitics. Covid-19. Racism. Racial Democracy.

Artigo recebido em: 2021-03-26Aprovado em: 20/11/2021

DOI: http://dx.doi.org/10.18764/2178-2865.v25n2p636-655

\footnotetext{
1 Graduação em Direito. Mestra em Políticas Públicas e Desenvolvimento Local (EMESCAM-ES). Discente de Formação Pedagógica em História e pós-graduando em Antropologia. E mail: eliaidinawagna@gmail.com
} 


\section{INTRODUÇÃO}

O Brasil, estruturado por uma cultura genocida, demarca-se pela exclusão dos corpos negros naturalizados nos espaços periféricos como seus lugares sociais por natureza. Suas humanidades foram expostas às marginalizações e desumanizadas não só pela omissão do poder estatal, mas por uma sistematização sociocultural direcionada aos descartes das sobras escravizadas que os distanciaram do acesso das políticas universalistas.

O descaso foi germinado por um processo de formação colonizada que hierarquizou, com influência do contexto escravagista, uma metodificação racial categorizada pela cor da pele, em cuja pirâmide fixou as pessoas de pele branca no pico da valorização e os escravizados a serviço da Colônia Europeia com a validação estatal movimentada em garantia dos privilegiados. Essa dinâmica encontrou o terreno fértil que sedimentou uma espécie de escalonamento de seres humanos tendo por base ciências pseudocientíficas de superioridade das raças.

Desde a imigração europeia, o uso da miscigenação voltada ao genocídio dos corpos negros até a dissimulada harmonia das raças, para a justificativa de ausência de medidas de inclusão positiva, a atuação brasileira se direciona ao enjeitamento dos resíduos do passado escravagista. Essa prática é permanente até os dias atuais, com uma política voltada ao segregacionismo em aberta manipulação da morte física, moral e civil de uma população negra marginalizada.

Este artigo dialoga com Borges (2020), Fernandes (2008, 2017), Foucault (2005), Gomes (2019), Nascimento (2016), Mbembe (2019), Miguel (2019) e outros autores a denunciar um necropoder atuante no genocídio dos corpos negros. As análises descritivas expõem políticas universalistas direcionadas a favor dos grupos dominantes e voltadas a uma atuação de aversão e intolerância que se opera em torno de uma necropolítica.

Aponta-se o necropoder como uma construção doutrinária a conceituar a prática de um poder soberano a serviço do genocídio de raças inferiorizadas pela visão elitista. Conclui-se pela necessidade de mais produções acadêmicas a expor o massacre dos negros brasileiros operado por intermédio de uma política da morte a usar mecanismos estatais para o segregacionismo racial.

Como ferramentas da necropolítica, a dissimulação de harmonia racial respalda ausências de políticas de inclusão social positiva e encarceramento em massa levando ao cultivo de condições mortiferas permanentes de minorias negras expostas à insegurança perene. Soma- se letalidades, 0 descaso político para com as favelas vulnerabilizadas, mais ainda com a recente pandemia do covid-19 que, embora causando a mortandade de milhares de brasileiros, mostra agressividade mais funesta sobre os corpos negros. 
A pandemia desnuda a decomposição proveniente do racismo estrutural e reclama mais atuação das políticas afirmativas para que o Brasil se direcione à efetiva democratização. Destaca-se que aos movimentos representativos agregam-se cada vez mais participações na busca de uma alteração desse quadro. Confere-se que a Constituição Cidadã é o instrumento que respalda a luta por igualdade material contra a atuação funesta da necropolítica.

\title{
2 DESENVOLVIMENTO
}

Um dos grandes impasses para a abolição já eram manifestos nas produções científicas e literárias com a preocupação explícita da elite intelectual temendo a deformação da qualidade do povo a ser organizado como a imagem dos nacionais do Brasil.A intelectualidade acadêmica foi contaminada pelas teorias de superioridade de uma raça sobre a outra, consoante se observa na declaração de Silvio Romero, já antes da abolição:

\begin{abstract}
Applicando as leis de Darwin à litteratura e ao povo brazileiro, é fácil perceber que a raça que ha de vir a triumphar na lucta pela vida, neste paiz, é a raça branca. A família selvagem e a negra, uma espoliada pela conquista, outra embrutecida pela escravidão, pouco, bem pouco, conseguirão directamente para si. [...] Uma cousa é para notar: eu desafio que me monstrem em toda história brasileira em quatro séculos, um só typo nacional, mais ou menos notavel, que haja sido negro ou caboclo puro. [...] o futuro deste paiz pertencerá definitivamente ao branco, só depois de haver assimilado os elementos estranhos indispensaveis para 0 habitarem a resistir plenamente às agruras de nossa natureza. (ROMERO, 1880. p. 48-50).
\end{abstract}

Silva (2019) relata que após a abolição, o sentimento a inquietar a sociedade escravista era 0 fim a ser dado aos libertos que eram percebidos como seres inferiorizados e mercadorias. Segundo a autora, o descontrole da importação negreira impossibilitou a devolução dos africanos à África, e a miscigenação preocupava um país que precisava destinar os corpos negros que ameaçavam a estruturação do domínio branco.

Naquele contexto, intelectuais e políticos defendiam de forma aberta e despudorada, a existência da hierarquização das raças. Os africanos livres assustaram a Colônia com a possibilidade de suas reproduções não serem mais controladas. A mão de obra gratuita extraída dos corpos negros, em um repente, converteu-se em resíduos que precisavam ser refreados diante da ameaça de formarem uma identidade nacional inferior aos olhos da Europa.

Surge a consagração do inimigo interno que representa, nos dias atuais, a imagem negra marginalizada e demarcada como propensa à delinquência, consoante definidos por Rodrigues (2010) em suas literaturas a respeito das raças negras que ele considerava degeneradas e criminosas pela própria essência. 
Nicollit e Lima (2020) descrevem que a superação do racismo pseudocientífico acreditado como hierarquia genética não significou a eliminação do racista crente na incapacidade de certos grupos em se adaptarem. $O$ pano de fundo da prática rácica é política e se volta à manutenção dos espaços e privilégios a um grupo dominante por meio da subjugação dos residuais. Verifica-se que no Brasil a questão racial foi germinada em uma hierarquia que serviu de base para toda a estruturação sociocultural e econômica do país.

Em termos estruturais, a naturalização dos negros na base da pirâmide socioeconômica assumiu contornos racialístico e serviu de barreira à ascensão social da população negra, bloqueando as oportunidades de competitividade no mercado de trabalho. Essa inferioridade, normalizada como inerente aos estoques raciais, Fernandes (2017), faz com que o protesto negro seja visto como algo ameaçador e fora da lei.

Destarte, a descolonialização não se desfez de suas raízes escravocratas e sedimentou, consoante Lemos (2018), políticas de inimizades sob a coordenação de uma estrutura jurídico-político e cultural assumindo um caráter de nítida depredação e submissão das vidas negras às práticas segregacionistas e genocidas. A autora analisa que as estigmatizações de categorias de subcidadania são uma realidade antagônica às sociedades democráticas, constituindo-se em um estado de exceção.

\subsection{A construção do inimigo interno e a segregação}

A par das práticas dos escravagismos serem tão antigas quanto a história da humanidade, Gomes (2019) relata que o maior diferencial do cativeiro africano para as demais escravaturas é que com a espoliação da África, o negro converteu-se no símbolo da desumanização de um grupo inferiorizado pela cor da pele. E, com isso, o fenótipo africano passou a ser a marca indelével da naturalização da sujeição de um povo com imediata visibilidade diante daqueles que os estigmatizaram como seres brutos em sua própria essência. Gestou-se, com a estigmatização, a encarnação do negro como escravo por natureza, um ser nascido para a serventia alheia, já não mais resultante das derrotas nas guerras.Essa imagem do preto servente é,até os dias atuais, a única de acesso do negro ao mundo branco.

A estigmatização negra naturalizou relatos como os de Rodrigues (2010) a declarar a questão de o negro ser mais do que uma modelação às condições da moral imposta pelo sistema escravocrata, mas uma inata incapacidade orgânica que não se permite a adaptação à civilização das raças superiores.Para o antropólogo, adepto das teorias das raças hierarquizadas, seria impossível aos ex-escravizados negros atingirem uma maioridade social que permitisse o convívio com os povos cultos, dadas às suas limitações biológicas congênitas. 


\section{O COVID-19 E AS VÍSCERAS DA NECROPOLÍTICA BRASILEIRA SOBRE A SAÚDE DOS CORPOS NEGROS}

Houve, assim, uma perversa preocupação com os descartes negros sob o medo de uma contaminação maléfica sobre a nacionalidade que se formava. A limpa do sangue brasileiro era a urgência que reclamava a entrada da imigração europeia para a purificação das raças. As vísceras desse racismo perverso ficaramexpostas nas declarações de João Batista Lacerda: "[...] não se póde (sic) negar que o demorado contato entre duas raças, uma atrazada (sic), outra adiantada, venha com o tempo fazer adquirir à raça adiantada, muitos dos vícios e defeitos da raça atrazada (sic)" (LACERDA, 1911, p. 90).

Antropólogo e delegado do Museu Nacional, João Batista de Lacerda pronunciou no Congresso Universal das Raças, reunidas em Londres em 1911, suas expectativas de que com a miscigenação, o Brasil seria um país de predominância branca em pouco mais de um século. Para esse mister, segundo ele, as esperanças do país foram creditadas no aumento das levas sucessivas de imigrantes europeus para a higienização dos sangues africanos.

Os discursos do antropólogo não foram uma opinião isolada, mas a retratação daquilo que sedimentou o pensar dos integrantes do poder no pós-abolição. Segundo Santos (2019), o pronunciamento de Lacerda (1911) foi endossado pela aprovação da diplomacia brasileira que, na voz de Manoel Oliveira Lima, exaltou os benefícios da imigração destinada à dissolução dos produtos negros pela superioridade europeia.

Assim, Santos (2019) relata que o pensamento de Lacerda (1911) recebeu o olhar cúmplice dos poderes dominantes. O processo imigratório objetivava, na realidade, transformar o Brasil em um viveiro branco e, assim, descartar as raças apontadas como degeneradas.Para tanto, a imigração branca foi incentivada, ao passo que as condições sub-humanas relegadas aos negros teve a atuação intencional do Estado com as expectativas de serem aniquilados.

Lacerda (1911) pronunciou, sem pudores ou qualquer desconforto, que a desorganização dos negros sem laços de união e embrutecidos, perdidos como animais criados sem rebanho e expostos a toda sorte de desgraças, entregues à incúria após a abolição, seria um trunfo para a redenção da identidade nacional. Esses ingredientes eram as condições mortíferas cultivadas de forma perniciosa para que a raça negra fosse levada à extinção sem grandes esforços do Brasil na solução desse considerado impasse. Diga-se que se referiam, no contexto, ao medo da formatação dos nacionais serem contaminados por uma considerada degeneração negra.

Observa-se que a expectativa era de que uma superioridade branca houvesse de sobrepor os escravizados libertos e trouxesse a prevalência da identidade europeia com sua cultura, valores e traços fenótipos. Seguiu-se então, após as secularidades do regime escravagista, uma política de segregação não oficializada, mas nítida, direcionada por práticas racistas a se encarregar em descartar os corpos africanos das terras brasileiras.Logo, o impasse que se demandou em relação 
aos escravizados libertos no pós-abolição, não se relacionou com a questão de como inseri-los no mercado de trabalho e integrá-los à plena cidadania como bem analisou Fernandes (2008a).

A temática negra, pelo contrário, tornou-se um estorvo, um problema a ser aniquilado porque consideradas como raças inferiores, os resíduos escravizados ameaçavam deformar a construção de uma nação saudável sob uma visão eurocêntrica.

Vastas são as documentações que comprovam as tentativas de, a todo custo, evitar a diminuição da influência negra na formação da identidade brasileira.Registra-se dentro dessas estratégias, que a imigração europeia incentivada pelo desejo de embranquecimento do povo brasileiro foi o traço marcante do racismo no Brasil. Contudo, o intento de se construir uma nova sociedade mediante essa higienização racial feita por intermédio do sangue branco na miscigenação, não obteve o êxito esperado, tendo em vista que passados 132 anos da abolição, o Brasil é, hoje, a segunda maior população negra do mundo.

Nascimento (2016) acusa, por essa razão, que o processo de miscigenação brasileira foi uma política eugenista e genocida que visou a estagnação da população negra pelo embranquecimento, ao mesmo tempo que delimitou o lugar social das raças. Percebe-se, todavia, que os efeitos negativos dessa política de descarte das gentes que foram subtraídas da África e desumanizadas, seguiu-se adiante com a ausência de condições para a concorrência com os imigrantes.

A indiferença para com os quase quatro séculos de embrutecimento a exigir políticas de adaptação, com acesso à educação e reforma agrária, inverteu-se com a adoção de medidas discriminatórias contra os extratos africanos, em intencionada segregação.

Fernandes (2008a) denuncia que os libertos foram convertidos em responsáveis por suas pessoas e descendência, mas não lhes dispuseram meios materiais e morais para assimilarem a economia competitiva. De modo que a abolição, na opinião do sociólogo, foi uma espoliação extrema e cruel dos negros largados ao penoso destino de se criarem após o longo confinamento. Esse processo, segundo ele, empurrou o negro para os setores residuais, limitados pelas deformações introduzidas pela longa escravização que não os condicionou à concorrência do sistema capitalista.

Constata-se, então, ingênua uma suposição de que as consideradas mercadorias seculares haveriam de ser humanizadas aos olhares da Colônia e dos dela descendentes, após séculos de desumanização. Simplório um pensar de que os donos das regras e dos meios de produção houvessem de enxergar nas gentes africanas agora libertas, seres humanos aptos para o trabalho produtivo em condições de igualdade nas celebrações de vínculos contratuais sem o uso da chibata.

Por isso é que Fernandes (2008) acusa que a sociedade brasileira largou o liberto ao seu próprio destino e, em concomitância, Ihes atribuiu as mazelas de suas desgraças. Observa-se, nessa 
omissão, um subterfúgio para se isentarem das culpabilidades para com 0 resultado das desumanizações seculares. Percebeu-se essa atuação do Estado a serviço dos interesses dos grupos dominantes, levantando uma política imigratória propensa à depreciação dos definidos como subprodutos do tráfico humano.

A ideia que se seguiu era da necessidade de se desfazerem das escórias escravizadas que já não mais se destinavam à mão de obra gratuita e, ainda, comprometiam a construção da identidade nacional. Aquele elemento negro, antes mãos e pés do Brasil, como disse Freyre (2019), tornou-se a prova incômoda da inferioridade brasileira diante de uma forte influência europeia de superioridade racial. Seguiu-se a política de descarte, conforme traçada nos manifestos da elite, como expostos por influentes como Lacerda, Oliveira Lima e outros.

Notaram-se os incentivos imigratórios destinados à substituição da mão de obra escrava, relegando negros aos guetos, sem trabalho e entregues à mendicância. Desse modo, a ausência de políticas inclusivas para os libertos, não se tratou de uma mera negligência ou falta de visão de uma época, mas de um ato político hediondo, deliberado e direcionado à eliminação dos resíduos negros e dos originários da terra.

Como dito, os africanos foram empurrados aos guetos.Soma-se a isso que a atuação legiferante (BRASIL, 1942) fez o encargo de criminalizar condutas tipificadas de vadiagem, provenientes da desocupação causada pelo desemprego. A capoeira foi também criminalizada (BRASIL, 1890). Até mesmo suas práticas religiosas seguiram o rumo da discriminação com acusação de serem demoníacas - o quesubsiste até os dias atuais:

\footnotetext{
Para evitar atritos com a Igreja Católica, os escravos, inspirados por entidades demoníacas, passaram a relacionar os nomes dos seus deuses - demônios, para ficar mais claro - com os santos do catolicismo romano. Assim podiam escapar da grande perseguição que a própria Igreja Católica moveu contra eles, após a proclamação da Lei Áurea (que libertou todos os escravos), por praticarem tais cultos. Daí os nomes das entidades estarem associados a santos, que na realidade nada têm a ver com eles. (MACEDO, 2019, não paginado).
}

Destarte, o Brasil adotou uma necropolítica direcionada ao afastamento e aniquilamento dos corpos negros e suas etnicidades, impulsionada por uma cultura de inferioridade que persiste à superação das ciências pseudocientíficas de hierarquização racial, e que tem como finalidade a manutenção dos espaços de poder no monopólio de um grupo.Contudo e para tanto, o jogo do poder é articuloso - em manipular,construir, desconstruir e reconstruir discursos, mas sempre no sentido de estruturar seu lugar de monopólio em detrimento da naturalização de um estado de marginalização permanente das gentes negras que "[...] no passado servia tão bem para trabalhar e apanhar [...]" (COSTA PINTO, 1998, p. 36), mas que foi convertido de utilidade para uma ameaça. 


\subsection{A necropolítica do segregacionismo como mecanismos de dissimulação de harmonia racial}

O necropoder consiste na política da morte. O termo, cunhado pelo filósofo camaronês Achille Mbembe (2016), relaciona a soberania como o poder de fazer morrer. Coloca-se no centro da reflexão, a discussão, os modos e formas pelas quais o poder político se apropria da morte como um objeto de gestão. É um conceito construído com interferência na definição de biopoder de Foucault.

Para Foucault (2006), o biopoder é referente aos limites da máxima soberania manifestada no controle sobre os corpos com definição de prioridades políticas para algumas existências em detrimento de outras. A teoria do necropoder desenvolvida por Mbembe (2016) sincroniza com a doutrina fourcatiana, e soma para definir que a máxima soberania decide quem e como morrer, mas atuando nesse sentido. Essa atuação é sentida de uma forma direta nos descartes das vivências demarcadas.

Trata-se de uma política voltada, com exclusividade, ao extermínio de corpos estigmatizados por relações de inimizades e mortes ditadas no sentido físico ou moral.Nessa concepção de Mbembe (2016), a necropolítica não se limita em apenas deixar morrer porque atua com intencionalidade de gerir as condições mortíferas a determinadas regiões e povos ao intervir no sentido de corpos demarcados e submetidos a um controle continuado. Essa gerência se volta ao necessário para sobrevivências em mínimas circunstâncias críticas.

Os negros, desumanizados pela política de constituição do inimigo interno, encarnam no imaginário, o perfil marginal e perigoso por natureza. Cria-se em defesa da sociedade e, em garantia da segurança dos privilegiados, um estado de exceção transformado em norma permanente a normalizar e naturalizar a quebra das garantias em relação a grupos previamente definidos.

De acordo com Mbembe (2016), o necropoder pode se fazer pela atuação de outros autores dentro ou de fora do desempenho estatal, mas inserido na rede de manipulação pela proliferação de condições mortíferas a determinados grupos. Adiciona-se, nessa lógica, que as tecnologias usadas pelos grupos dominantes podem operar necropoliticamente, como é o caso da dissimulação de harmonia das raças.

No caso do Brasil, o necropoder viu o pós-abolição operado na substituição da mão de obra negra pelos imigrantes brancos com o claro desejo de desaparecimento dos libertos por meio da miscigenação e da pauperização proveniente da ausência de políticas públicas. Ainda, essa necropolítica repara-se no menoscabo com que os libertos foram jogados nas periferias e criminalizados com a instituição do inimigo interno.

Verificou-se mais, a necropolítica na atuação legiferante para a marginalização de culturas, manifestações religiosas e até destinos dos negros, ao tipificar crimes como a vadiagem 
(BRASIL, 1941). Todas essas tecnologias atuaram na naturalização da imagem negra marginalizada e encarcerada, com a clara intenção de segregar e confirmar suas mortes físicas ou morais.

Também, e em principal, o necropoder é manifesto sob o manto da harmonia das raças. Membros do poder e da sociedade impregnaram a teoria do inimigo imaginário aos corpos negros que foram naturalizados com a pecha de agentes delinquentes.Essa é a assertiva de Miguel (2019), apontando o encarceramento em massa da juventude negra como o caminho para a segregação e suspensão de vidas que encontrou na Lei de Drogas, a porta escancarada para 0 aprisionamento seletivo de jovens pardos e pretos.

Para Borges (2020), a conformalização do inimigo penal interno foi personificada nas classes populares e desenvolvidas com a perspectiva de que as camadas negras e seus descendentes fossem o perigo que ameaça a propriedade e que, por isso, precisam do controle social.Observa-se, contudo, que sob a égide da Constituição Cidadã (BRASIL, 1988), o discurso adotado para a segregação se volta a uma justificativa de que as medidas de segurança são planejadas para se garantir uma (des)ordem social em que 0 acesso aos direitos fundamentais não alcançam os grupos marginalizados.

Sob essa lógica, pode-se apontar a ideologia mitológica da democracia racial como a mais eficiente das tecnologias do necropoder brasileiro. Essa dissimulação de harmonia potencializa 0 refreamento das medidas reparatórias de redução das desigualdades raciais e isenção das políticas de ações afirmativas, reproduzindo 0 ambiente de privilégios com negação dos fatores que vitimaram e vitimam os negros.

Recapitula-se o dizer de Fernandes (2008a) ao denunciar que com a súbita alteração das relações de produção e organização da sociedade, os negros quedaram-se apáticos porque se viram excluídos da prosperidade sem condições de sustentar as regras competitivas do mercado.A situação de apatia do negro, pela pauperização a ele imposta, era o fruto da desesperança, um estado de anomia que transportou as misérias do cativeiro e constituiu uma congérie social dispersa.

Fernandes (2008a) expôs análises dos fenômenos de desenvolvimento brasileiro pósabolição para explicar o pauperismo do negro e como essa catástrofe foi articulada para se interpretar como um estilo de vida e ajustamento normal dessas comunidades ao mundo urbano, cujas misérias foram julgadas como o resultado de uma herança biológica e o peneiramento negativo da etnia.

Nascimento (2016) acusa, por isso, a dissimulação de harmonia das raças como estratégia para a manutenção da população negra no estado de miséria em que se encontra. Segundo o Autor, ao afirmar que no Brasil não imperou segregação e as raças sociais convivem em democracia, o Estado se isenta de medidas reparatórias, jogando sobre os ombros dos negros seus próprios infortúnios. 
Com isso, Fernandes (2008a) considera que o extinto regime escravocrata não se aboliu das mentalidades e se manteve nítido no comportamento e no imaginário para os quais negros são tidos como seres limitados. Decorre, daí, que suas oportunidades são empurradas para tarefas residuais como única via de acesso ao mercado de trabalho.

Acrescenta-se nessa discussão, a naturalização de superveniente do negro a resultar que mesmo em nível educacional equivalente com membros da população branca, ainda assim a concorrência é desigual por força do racismo, consoante dados do IBGE - Instituto Brasileiro de Geografia e Estatística (BRASIL, 2019).Em vista disso, apura-se que além de ser negada ao negro condições de ajustamento na sociedade competitiva após gerações de confinamento e coisificação, a sociedade brasileira atribui os méritos e fracassos a uma meritocracia sob o argumento de inexistência de discriminação racial.

A ausência de um apartheid oficial foi uma tecnologia da necropolítica articulada para impor obstáculos às discriminações positivas e garantir os espaços de poder aos grupos dominantes com negação de paridades, em que a chamada tolerância racial do brasileiro, no conceito Nascimento (2016), implicava em uma tolerância maior por parte dos negros, uma forma de condescendência com os privilégios dos brancos (NASCIMENTO, 2016, n. p.).

A respeito dessas desigualdades, os mais recentes dados fornecidos pelo Instituto Nacional de Pesquisa por Amostra de Domicílios Contínua de 2018 apontam relativa desvantagem para a população negra em todos os setores da qualidade de vida. Segundo o IBGE (BRASIL, 2019), as desigualdades raciais ultrapassam a questão de classe e gênero com desvantagem dos povos negros em escalas totais.

Fontes do IBGE (BRASIL, 2019) assinalam que as disparidades no padrão das vidas negras em relação às pessoas brancas se observam em todos os setores. Confere-se, nisso, 0 resultado de a população negra ter um histórico de assujeitamento às encostas periféricas, sem igual acesso às políticas universalistas de educação, saúde, transporte, saneamento básico, segurança pública e lazer.

O que se vê é o resultado de um Estado a priorizar o bem-estar dos lugares nobres em detrimento dos espaços periféricos de alta densidade negra. Esse cenário é a consequência de corpos de negros e favelados serem naturalizados na condição marginal, com criminalizações direcionadas às segregações específicas. Essa ação segregacionista secular formatou os piores lugares para as populações negras, em todos os estratos sociais.

Destarte, mesmo quando negros e brancos se mantenham no mesmo recorte de nível acadêmico, a despeito de a população negra representar a maior força de trabalho no país por ser mais 
numerosa, o acesso da cor marginalizada ao mercado de trabalho é operado em desvantagem muito mais ligada ao problema racial do que questão de qualificação.

Essa polêmica, inclusive, ganhou dimensão em redes sociais que convém acrescentar nesse trabalho. Menciona-se a recente declaração da cofundadora do Nubank ${ }^{1}$, Cristina Junqueira que em entrevista ao programa Roda Viva, no dia 19 de outubro de 2020, declarou que tem dificuldades em encontrar candidatos negros para preenchimentos de vagas de liderança da empresa e, por isso, a contratação não atenderia as exigências empresariais e exigiria um "nivelamento por baixo" (JUNQUEIRA, 2020).

Observa-se nos dados acima que de todos os argumentos, esse é o que mais pesa contra a proclamada democracia racial brasileira.Notabiliza-se que a segregação vai além de fatores educacionais afetos às divisões de classes. Atinge-se o cerne do problema que é a discriminação em razão da cor da pele, porque ao contrário do que diz Junqueira (2020), mesmo em condição de equivalência acadêmica, a população negra é preterida.

Constata-se, então, que qualquer que seja ohistórico acadêmico, o indivíduo de pelenegra estará sempre em desvantagem na concorrência com pessoas de pele brancanesseracismo estrutural que comanda a sistematização da sociedade brasileira. De modo que as disparidades não se relacionam apenas à problemática de classe, porqueo segregacionismoé, sobretudo, o racismo de uma sociedade que se nega em reconhecer a plena cidadania à população negra.

À vista disso, em tempos atuais, existe o remanejamentonas manifestações do racismo deslocando sua retórica com manutenção do trato. Antes, uma elite intelectual mal dizia abertamente a presença dos libertos na composição da identidade nacional. Agora, o mito da democracia racial é convertidoempolítica para odescrédito das reivindicações representativas em favor das medidas de inclusão positiva, mas sempre sedimentando a imagem do negro marginal. Porque essas tecnologias negam a anomia e pauperismo populacional negro como o produto das políticas segregacionista.

Frustradas as políticas de extinção africana pela miscigenação, a segregação socioeconômica que empurra corpos negros para as favelas já não basta. O Estado Brasileiro, a serviço de alguns grupos dominantes, mantém a atuação de um necropoder de exterminação realizada por meio de tecnologias como o encarceramento em massa cujoaparato policial ejudiciário seconvergemna suspensão das vidas negras (MIGUEL, 2019, n. p).

Foi essa segregação que Miguel (2019) constatouna seletividade capixaba no combate às drogas. Em pesquisa a vários processos criminais referentes a prisões por drogas, o Autor registrou que a imensa maioria dos magistrados não se lembravam de sequer uma apreensão que não fosse nos locais periféricos. Também, nas entrevistas, ficou explícito que os juízes capixabas consideram como 
pontos de drogas os bairros da periferia, lógica que não se aplica aos lugares nobres, como se as classes médias/alta não consumissem drogas e nem traficassem.

Pode-se, com isso, observar que a presença estatalno controle social é implementada mediante violação das garantias constitucionais de proteção contra os corpos marginalizados sob o argumento de segurança pública, mas com uma seletividade violenta contra os negros e favelados que, na maioria das vezes, são identificações dos mesmos corpos. Isso porque nas favelas, a presença negra é densa; nesses locais é onde mais severifica a deficiência daspolíticas universalistasreferentes a saúde, educação, segurança pública, transporte e outros. Esses desprovimentos deixamos moradores das periferias mais expostos às condições mortíferas permanente.

No mais das vezes, as moradiasdas favelas são conjuntos de habitações precárias em que suas comunidades retratam uma subsistência de densainformalidade. Esses espaços urbanos periféricos são os resquícios da colonização que aparelhou o poder transportando seu modelo de hierarquização aos dias atuais, com a retratação dos moradores favelados por uma maciça presença negra.

\subsection{A necropolítica operada na exposição dos corpos negros à mortalidade pandêmica do covid-} 19

Com a recente pandemia do covid-19 que parou o planeta compelindo a humanidade ao distanciamento social, os jornais noticiaram uma mortandade reproduzida em um alastramento que assustao mundo. No Brasil, esse isolamento é quebrado pelos grupos sociais por diversos motivos. De um lado, o privilégio das classes dominantes ao acesso facilitado de recursos médicos parece fornecer uma sensação de imunidade. Na outra ponta, os trabalhadores informais, que precisam da lida diária para a sobrevivência, chocam com a complexa realidade das famílias dividindo espaços pequenos.Nesse grupo, acumula-se a imensa massa das comunidades negras.

A Fundação Oswaldo Cruz - FIOCRUZ desenvolveu uma análise da frequência, incidência e letalidade por Covid em favelas cariocas. Consoante mencionado boletim socioepidemiológico analisando dados oficiais disponibilizados pela prefeitura municipal do Rio de Janeiro, Ângelo, Leandro e Perissé (2020) indicam que nas áreas com maior concentração de pobreza urbana, a propagação da doença por COVID-19 avança de forma mais acelerada.

A questão da mencionada análise, de acordo com Ângelo, Leandro e Perissé (2020), é que esses territórios são mais deficientes na proteção coletiva por ter menos acesso às políticas públicas. Também as condições de vida dos favelados dificultam a adoção das estratégias preventivas como o distanciamento social. Dentre as razões dessas dificuldades de cumprir 0 isolamento, os 
autores apontam que o contingente populacional dos moradores da favela são trabalhadores informais sem nenhuma garantia trabalhista.

Pechim (2021) denuncia que os homens negros são os que mais morrem pela covid-19 e as mulheres negras são as mais afetadas. Entre os motivos, aponta-se que as populações compõem $67 \%$ dos brasileiros que dependem com exclusividade do SUS - Sistema Único de Saúde. Além do mais, esses grupos moram e trabalham em condições precárias em atividades que não podem ser remotas.

Baruty (2020) reclama, com isso,a necessidade de políticas preventivas direcionadas às pessoas negrascom intensificação prioritárias de planos de testagem em massa e atendimento voltados ao acolhimento específicos.Observa-se essa defesa de priorização dentro da lógica estatística que revela serem os negros a camada de maior vulnerabilidade na exposição das doenças contagiosas por fatores socioeconômicos, exigindo-se especial proteção diante da ineficiência daspolíticas universalistas.

Contudo, e não obstante o alerta quanto aos reflexos nocivos das desigualdades sociais a representar disparidades na mortandade da população negra em relação às pessoas brancas, 0 governo não apresenta nenhuma proposta de contenção, ainda que as repercussões do covid19 considerem dimensões políticas, econômicas, urbanísticas e habitacionais.Com essas observações, dois grupos expressam suas desigualdades delineadas no tecido socioespacial, cujas periferias foram desnudadas pela pandemia (BIENENSTEIN; BIENENSTEIN; SOUZA, 2020, n. p.).

A questão não passa somente pelo isolamento social ser mais difícil aos negros moradores das favelas vivendo em espaços reduzidos e divididos com muitos-o obstáculo é que a imensa maioria das favelados vivem na informalidade e não podem parar, senão não comem. Agravase a situação, o fato de que os moradores periféricos são dependentes de transportes públicos precários e lotados que aceleram a propagação do vírus.

Andrade (2020) exclamao cenário de adversidades contrárias ao cumprimento da quarentena pelos moradores das periferias, de tão surreal, faz pensar que "[...] Não estamos muito longe dos brioches da rainha francesa ao indicar que se fique em casa, evitemos multidões, usemos álcool gel em abundância e Trabalhemos em casa" (ANDRADE, 2020, n.p.).

O autor expõe que devido ao isolamento, os serviços de entrega foram multiplicados e, com as contratações por dia, brotaram serviços temporários. Assim, a pobreza sem emprego formal e transporte digno se mobiliza ainda mais no trabalho na intenção de propiciar a quarentena dos privilegiados. 
Via de consequência, os moradores da periferiaficam mais expostos ao vírus e, com isso, a proliferação da peste é maior nas favelas porque lá o distanciamento social é dificultado por fatores de logística e menor acesso aos serviços públicos, impactando na infecção e propagação da doença.

Destarte, os populares das comunidades periféricas, depreponderância negra, não podemseresguardar no isolamento. Os trabalhadores que coletam o lixo público e fazem as entregas a domicílio das compras realizadas via telefone e internet em garantia de outras comodidades necessárias ao cumprimento da quarentena da classe média e alta, em sua imensa maioria são favelados.

A respeito, Santos e Rosa (2020) lembram que o primeiro registro de vítima do covid-19 foi uma empregada doméstica que atendia a casa de moradores recém-chegados de uma viagem à Itália já contaminados e que sequer dispensaram a subalternaou lhecomunicaram do risco de contaminação. As autoras dizem que embora os jornais omitissem a cor da falecida, os marcadores sociais já indicam que as mulheres negras compõem a presença maciça no serviço doméstico.

Borges (2020) chama a atenção para esse processo de exposição dos corpos negros a serviço do outro, de violência. Segundo a autora, trata-se de uma marginalização política e econômica da população negra, definindo ser esse o pilar das práticas sociais provenientes da colonização que encerrou dicotomias categorizadoras dos grupos humanos e não humanos. Cita-se, a exemplo, conforme o trabalho desenvolvido por Borges (2020), um estudo do Núcleo de Operação e Inteligência em Saúde da PUC-Rio em que se constata o avanço da pandemia atuando mais mortífera sobre os corpos negros: "[...] Dos cerca de 30 mil casos graves estudados pelo grupo até maio de 2020, 55\% dos negros morreram. Entre brancos, essa porcentagem ficou em torno de 38\%" (BORGES, 2020, n.p.).

Ampliando a colocação de Borges (2020) de que a pandemia seria uma lupa da questão prisional brasileira, pode-se afirmar que os efeitos da contaminação escancaram toda a sistematização socioeconômica do país no que se refere aos efeitos funestos da cultura rácica.Para a autora, a máscara da negação do racismo se faz presente nas análises dos dados de um país que teima em maquiar a necessidade de expansão das políticas específicas, argumentando que a pobreza é a causa das mortes de mais negros por covid-19 e outras fatalidades. A respeito, a ativista menciona: "[...] Só esqueceram de dizer que pessoas negras são pobres porque são negras" (BORGES, 2020, n.p.).

Dessa forma, Borges (2020) delata que as desigualdades da realidade extramuros são aprofundadas nos contextos prisionais de intensificada desumanização que aciona o encarceramento em massa.Aautora denuncia que o Brasil consta dentre os cinco países com mais contaminações de presos, constatando-se 123.269 confirmações de covid-19 até o dia 14 de julho de 2020 e 1.485 óbitos contabilizados. Contudo, existe uma falta de transparência das informações que colocam os presídios como uma "caixa preta" em uma ambiência apropriada para a disseminação do vírus. 
Essa assertiva é respaldada nos graves problemas de infraestrutura prisionais com superlotação e prestação precária de assistência à saúde, cujas unidades carecem, em sua maioria, de médicos e enfermarias, além de falta de medicamentos, convívio com esgoto abertoe cortes no abastecimento de água. Todas essas causas já faziam com que doenças tratáveis como tuberculose, aids e diversas infecções se tornassem fatalidades dentro das penitenciárias.

Retornando à realidade extramuros, uma outra questão aflige corpos acostumados a serem apontados como o inimigo interno. Santos e Rosa (2020) alertam que dentre as medidas sanitárias preventivas, as máscaras que cobrem parcialmente o rosto para se evitar o contato de áreas da mucosa esbarra nas políticas de segurança pública que elegeu o negro como o marginal e prossegue com intensa violência policial nas operações realizadas nos territórios favelados em plena pandemia:

O uso de máscaras em territórios em que o racismo faz parte do modo de organização da sociedade produz efeitos outros, desconhecidos para aqueles que propõem as máscaras como cuidado sanitário universal. A máscara, acoplada ao corpo negro, pode trazer o medo da morte. Seu esquema epidérmico racial, aprendido através do racismo cotidiano, indica a este corpo que, para se proteger, ele precisa tirar a máscara. A Covid-19 expõe como é profunda e irracional a desigualdade racial em que estamos inseridos. (SANTOS; ROSA, 2020 , n. p.).

A formatação dos corpos negros na retratação do inimigo interno, somadaàs permanentes normalizações das revistas policiais nesses agentes sinalizadoscomo os suspeitos por natureza, confereao negro a internalizaçãodesses estigmas. Por isso, Santos e Rosa (2020) levantam a questão de que mesmo os aparatos de prevenção contra a transmissão do vírus, como é a máscara racial para limitação do contágio, intensificam aexposição dos negros a mais um plus de violência em razão da estigmatização construída em torno dosseus corpos expostos à marginalização.

Essa preocupaçãode Santos e Rosa (2020) é expressada no desabafo de Cipó (2020) no twitter. Avista-se nele a retratação de um homem negro que diante de um assalto próximo a ele, teve como primeira reação retirar a máscara de imediato, antes mesmo de correr em busca de proteção. Foi 0 instinto protetivo de se mostrar a quem quer que fosse, para expor a terceiros que não seria ele 0 assaltante: "Domingo meio-dia, estoura um assalto a loja, do meu lado. Meto o pé correndo. Por um segundo, minha reação: tirar a máscara pra ninguém achar que foi eu. Que inferno!"(ROGER CIPÓ, 2020 , n.p.).

Trazendo a superfície a soma de todas os reflexos da política rácica a projetar a necropolítica, Silva e Adriano (2020) declaram que as feridas do colonialismo tornaram os corpos dissidentes, alvo de uma violência sistemática do Estado. Os autores denunciam que a pele negra se tornou o signo da morte, com alta densidade sobre o homem jovem negro, configurando-se em um verdadeiro genocídio. 
O regime escravagista indissociável da nossa históriapenetrou nosso tecido social tão firme e tenaz, que soa autêntica a declaração de Santos (2020): "Acostumamo-nos a naturalizar a morte do negro. Ignoramos não somente a sua dor, mas também o seu extermínio" (SANTOS, 2020, n.p.). O autor enfatiza que o papel do Estado no fortalecimento do racismo é nítido quando se verifica que a força estatal é a detentora da legitimidade do poder, mas que ao invés de atuar na redução das desigualdades, noticia-se nas mídias, o assassinato cotidiano de jovens negros pelas forças armadas.

Nicolitt e Lima (2020) denunciam que, em termos de segurança, enquanto para uns a presença do Estado significa proteção, para outros ela significa a morte. Os autores alertam que a imagem negra constituída no inimigoalimentaa sensação de segurança do sobrevivente com as mortes e segregações negras. "Uma lógica de segurança pública fundada na necropolítica garante, para alguns, o gozo dos direitos, enquanto, para outros [...] materializa o permanente estado de exceção. (NICOLITT; LIMA, 2020, n. p.).

Por conta disso, Santos e Rosa (2020) mencionam que em uma enquete online feita com negros, cuja pergunta girou em torno de: 0 que se faria se 0 racismo acabasse. As respostas mais curtidas giraram em torno de: a) ir ao centro comercial de chinelo e abrir a bolsa dentro da loja; b) não ter medo da polícia e c) correr na rua tranquilo. Desse modo, nota-se que ações de segurança pública universalista atuam contra os negros em uma declaração de guerra com tamanha influência que para a cor sinalizada e etiquetada com a imagem do inimigo interno, o pânico da presença policial gera maior temor do que a contaminação da peste.

\section{CONCLUSÃO}

Parece óbvio que o covid-19 não atua com preferência na população negra. 0 vírus tem se mostrado democrático em contaminar sem distinção. Contudo, a soma das políticas de exclusão impostas no contexto histórico e contemporâneofoi construída em uma sistematização propícia a tornar corpos negros, uma estufa para a proliferação com caminho certeiro para a morte. São as garras da necropolítica com suas vísceras expostas pela pandemia. A vulnerabilidade social da população negra foi gerada e germinada por uma política de caráter segregacionista proveniente de uma necropolítica que nunca se direcionou àintegração do negro no sistema competitivo. Ao contrário, a imigração tratouse de uma medida comclara intenção de extermínio dos corpos negros marcados para morrer em razão de uma suposta insegurança perene sentida pela elite com a fertilização do inimigo interno no imaginário popular.

O racismo que estruturou nossa sociedade em termos históricos, políticos e sociocultural é uma venda colocada nos olhos para se alienar e impedir que o Estado Democrático de Direito avance e 
se manifeste em uma verdadeira democracia. Todavia, aquilo que aparenta ser um ganho para os grupos sociais privilegiados, em termo de constituição da identidade nacional, representa um atraso porque o racismo retira detodos a dignidade.Essa constituição do inimigo internoretira a essência de direitos e deveres que constituem a cidadania verdadeira na consciência coletiva. $O$ que preocupa é que a sensação de segurança coletiva trazida pelos aparatos estatais não passa de mera ilusão na medida em que violência gera violência.

O covid-19 desvenda uma sociedade debilitada de valores, onde a maior fatalidade contra os corpos negros não é a pandemia, maso organismo social doente que elege os seus inimigos nos corpos alheios marcados por estigmas. Essa sistematização classista, elitista e racista entrava o desenvolvimento nacional em termos sociais, em tempos em que democracias são reconhecidas pelo compartilhamento dos espaços com condições mais igualitárias.

Nesse caminho, as produções acadêmicas cumprem importante papel na denúncia das mazelas que impedem a constituição efetiva de um Estado Democrático de Direito que só seconcretizarácom o reconhecimento da cidadania de todos. 0 caminho é longo, e a pandemia, ao escancarar o quadro de aprofundada segregação, denuncia a necessidade de urgentes políticas afirmativas de caráter público e privado.

Mas a concretização dos ideais proclamados pelo Estado Democrático de Direito exigedos movimentos representativos um ativismo organizado com a compreensão dos mecanismos que instrumentalizam as garantias dos direitos fundamentais da dignidade da pessoa esculpidas na Carta Cidadã. $O$ amadurecimento da democracia é a excelência a ser alcançada por meio da consciência dos nacionais, do estado de apatia que subjuga corpos negros e retira, do Brasil,o caráter deEstado cidadão.

\section{REFERÊNCIAS}

ANDRADE, Carlos Fernando. O vírus em um cenário de descidade. In: O coronavírus, a cidade e a arquitetura: o caso brasileiro como um [possível] laboratório de horrores. In. BORGES, Andrea; MARQUES, Leila (orgs.). Coronavírus e as cidades no Brasil: reflexões durante a pandemia. Rio de Janeiro: Outras Letras, 2020.

ÂNGELO, Jussara Rafael; LEANDRO, Bianca Borges da Silva; PERISSÉ, André Renaldo Santos. Boletim socioepidemiológico da Covidnas favelas: análise da frequência, incidência, mortalidade e letalidade por COVID-19 em favelas cariocas. 2020. Disponível em:https://www.arca.fiocruz.br/handle/icict/42322. Acesso em: 26 set. 2020.

BIENENSTEIN, Glauco; BIENENSTEIN, Regina, SOUSA, Daniel. 0 coronavírus, a cidade e a arquitetura: 0 caso brasileiro como um [possível] laboratório de horrores. In: Coronavírus e as cidades 
no Brasil: reflexões durante a pandemia. Andrea Borges, Leila Marques (orgs). Rio de Janeiro: Outras Letras, 2020.

BORGES, Juliana. A pandemia é uma lupa para os problemas nas prisões. [S. I.]: Todavia. 2020.

BRASIL, Decreto n. ${ }^{\circ} 849$ de 11 de outubro de 1890, publicada em 13 dez. 1890. Disponível em:http://www.planalto.gov.br/ccivil_03/decreto/1851-1899/d847.hhtm Acesso em:17 set. 2020.

BRASIL, Decreto-Lei n. ${ }^{0} 3.688$ de 3 de outubro de 1941. Publicada em 3 out. 1941. Disponível em:http://www.planalto.gov.br/ccivil_03/Decreto-Lei/Del3688.htm. Acesso em: 14 set. 2020.

BRASIL, Constituição da República Federativa do Brasil. Publicada em 18 de out. 1988. Disponível em:

https://www.google.com/url?sa=t\&source=web\&rct=j\&url=http://www.planalto.gov.br/ccivil_03/constituic ao/constituicao.htm\&ved=2ahUKEwj8rlzq-YzsAhXglLkGHUdZApYQFjAAegQIERAD\&usg=AOvVaw00cDf3dib8KbUFGgSkZCp. Acesso em: 28 set. 2020.

BRASIL, PLANALTO. Lei 11.343 de 23 de agosto de 2006. Publicada em 23 agot. 2006. Disponível em: http://www.planalto.gov.br/ccivil_03/_ato2004-2006/2006/lei//11343.htm.Acesso: 02 out. 2020.

BRASIL, IBGE. Desigualdades Sociais por Cor e Raça no Brasil.Estudos e Pesquisas. Informação Demográfica e Socioeconômica. $\boldsymbol{n} .^{0}$ 41.Publicada em 2019. Disponível em:

https://www.google.com/url?sa=t\&source=web\&rct=j\&url=https://biblioteca.ibge.gov.br/visualizacao/livro s/liv101681_informativo.pdf\&ved=2ahUKEwinwKOxpOzrAhWQF7kGHf9-

Dn0QFjABegQIARAB\&usg=AOvVaw0p4_luQbofYfsNiDZhVf8u\&cshid=1600211661881. Acesso em: 15 set. 2020.

CIPÓ, Roger. Domingo meio-dia, estoura um assalto a loja, do meu lado. Meto o pé correndo. Por um segundo, minha reação: tirar a máscara pra ninguém achar que foi eu. Que inferno! Disponível em: https://mobile.twitter.com/rogercipo/status/1262039515822161921?lang=bn. Acesso em: 26 set. 2020.

COSTA PINTO, L. A. 0 negro no Rio de Janeiro: relações de raça numa sociedade em mudança. Rio de Janeiro: EDUFRJ, 1998.

FERNANDES, Florestan. A Integração do Negro na Sociedade de Classes: o legado da raça branca, v. 1. 5. ed. São Paulo: Globo, 2008.

FERNANDES, Florestan. SIGNIFICADO DO PROTESTO NEGRO.São Paulo: Expressão Popular. 2017.

FREYRE, Gilberto. Casa-grande \& senzala: formação da família brasileira sob o regime da economia patriarcal. São Paulo: Global, 2019.

FOUCAULT, Michel, Em Defesa da Sociedade Curso no Collège de France (1975-1976). Tradução de Maria Ermantina Galvão. São Paulo: Martins Fontes. 2005.

GOMES, Laurentino. ESCRAVIDÃO. Do primeiro leilão de cativos em Portugal até a morte de Zumbi dos Palmares. Rio de Janeiro: Globo Livros. 2019. 
JUNQUEIRA, Cristina. RODA VIVA. Cristina Junqueira sobre a entrada de pessoas negras no mercado. Publicada:19 out. 2020. Disponível em:

https://www.google.com/search?q=cristina+junqueira+nubank\&oq=cristina+jun\&aqs=chrome.3.0i355i43 3j46i433j69i57j0i131i433j0.5802j0j4\&client=tablet-android-samsung-nf-rev1\&sourceid=chromemobile\&ie=UTF-8\#. Acesso em: 30 out. 2020.

LACERDA, João Batista. Sobre os mestiços brancos. [S. I.]: Museu Nacional Biblioteca. 1911. Disponível em: www.museunacional.ufrj.br > obras...Biblioteca Digital do Museu Nacional. Acesso em: 9 set. 2020.

MACEDO, Edir. Orixás, caboclos e guias: deuses ou demônios? 6. ed.São Paulo: UNIPRO EDITORA, 2019.

MBEMBE, Achille. Biopoder soberania estado de exceção política da morte. Rio de Janeiro: Revista do PPGAV/EBA/UFRJ n. ${ }^{0}$ 32. 2016. Disponível em:

https://www.google.com/url?sa=t\&source=web\&rct=j\&url=https://revistas.ufrj.br/index.php/ae/article/view 18993\&ved=2ahUKEwiDyZ6lhOLrAhX3JLKGHQ-

ZADAQFjABegQIAxAB\&usg=AOvVaw0aTBvLYYYNO2Aq6LSdl2Xj. Acesso em: 11 set. 2020.

MIGUEL, E. C. A lei não é para todos: a seletividade penal da lei de drogas na Grande Vitória. Vitória: Editora Milfontes, 2019.

NASCIMENTO, Abdias do. 0 genocídio de negro brasileiro: Processo de um racismo mascarado, 1. ed., São Paulo: Perspectivas, 2016.

NICOLITT, André; LIMA, Paulo Henrique. De tigres a tiros:negros, segurança pública e necropolítica. In. De bala em prosa Vozes da resistência ao genocídio negro. [S. I.]: Editora Elefante. 2020.

NUNBANK.Conta do Nubank.Nossa conta digital com mais de 20 milhões de clientes em todo Brasil. 2021. Disponível em: https://www.google.com/url?sa=t\&source=web\&rct=j\&url=https://nubank.com.br/\&ved=2ahUKEwjatrXzvt zsAhVEEbkGHUONCfOQFjAAegQIEBAD\&usg=AOvVaw3_hb_IJ1VTX-VJGYhw5X5J. Acesso em: 06 fev. 2021.

PECHIM, Lethicia. Negros morrem mais pela covid-19. Pretos e pardos também têm mais chance de serem infectados e correm mais risco de hospitalização.Publicada em 20 nov. 2020. Disponível em:https://www.medicina.ufmg.br/negros-morrem-mais-pela-covid-19/. Acesso em: 6 fev. 2021.

RODRIGUES, Nina. Os africanos no Brasil. Rio de Janeiro: Centro Edelstein de Pesquisa Social, 2010.

SANTOS, José Geraldo dos. Manoel Bonfim (1868-1832) e Manuel Oliveira Lima (1867-1928): duas leituras sobre o pan-americano e a América Latina. Anais da Jornada de Estudos Históricos Manoel Salgado PPGHIS - UFRJ, 14 ed., v. 5, Rio de Janeiro, 2019. Disponível em:

https://www.google.com/url?sa=t\&source=web\&rct=j\&url=https://www.jornadaeh.historia.ufrj.br/wpcontent/uploads/2020/01/JOS\%25C3\%2589-GERALDO-DOS-SANTOS_JORNADA_2019Jos $\% 25$ C3\%25A9-Geraldo-Silva-

1.pdf\&ved=2ahUKEwiLsI3H6eHrAhUCGrkGHaXaAd0QFjAAegQIBBAB\&usg=AOvVaw0SLGt91n6aOs7 _A_q7_Cqf. Aceso em: 11 set. 2020. 
SANTOS, Lucas Gabriel de Matos; ROSA, Pedro. Máscara e homem negro: entre o contágio e o racismo em um regime necropolítico. Psicologia\& Sociedade. Psicol. Soc. v.32. Belo Horizonte. 2020. Disponível em: https://www.scielo.br/scielo.php?pid=S0102-

71822020000100416\&script=sci_arttext. Acesso em: 23 set. 2020.

SILVA, Eliaidina Wagna Oliveira da. Quem é negro no brasil? o lugar do pardo e a situação das cotas. In: Judicialização das ações afirmativas de cotas para negros nas universidades. Dissertação (Mestrado) em Políticas Públicas e Desenvolvimento Local. Orientador César Albenes de Mendonça Cruz. 112 f. 2019. Disponível em: http://www.emescam.br/mestrado/dissertacoes-defendidas/turma2019/. Acesso em: 26 set. 2020.

SILVA, Vinícius; ADRIANO, Victor. "A gente combinamos de não morrer": retornar às raízes e (re)construir espaços de afeto para o nosso povo. In: De bala em prosa: vozes da resistência ao genocídio negro. [S. I.]: Editora Elefante. 2020.

\footnotetext{
${ }^{1}$ Trata-se de um banco 100\% digital e voltado para ser a instituição bancária do futuro.
} 